\title{
One-Step Microemulsion-Mediated Hydrothermal Synthesis of Nanocrystalline $\mathrm{TiO}_{2}$
}

\author{
Xuyao Xu, Xiaosong Zhou*, Lin Ma, Miaoyan Mo, Cuifen Ren, Rongkai Pan \\ School of Chemistry Science \& Technology, Institute of Physical Chemistry, and Development Center for New \\ Materials Engineering \& Technology in Universities of Guangdong, Zhanjiang Normal University, Zhanjiang, \\ China \\ Email: zxs801213@163.com
}

Received 18 January 2014; revised 18 February 2014; accepted 25 February 2014

Copyright $@ 2014$ by authors and Scientific Research Publishing Inc.

This work is licensed under the Creative Commons Attribution International License (CC BY).

http://creativecommons.org/licenses/by/4.0/

(c) (7) Open Access

\begin{abstract}
Nanocrystalline $\mathrm{TiO}_{2}$ powders with high photocatalytic activity were prepared by one-step microemulsion-mediated hydrothermal method using tetrabutylorthotitanate $\left(\mathrm{TiO}\left(\mathrm{C}_{4} \mathrm{H}_{9}\right)_{4}, \mathrm{TBOT}\right)$ as precursor. The as-prepared $\mathrm{TiO}_{2}$ powders were characterized by $\mathrm{X}$-ray diffraction (XRD), transmission electron microscopy (TEM) and the Brunauer-Emmett-Teller (BET) specific surface area measurements. The effects of the oil/water ratio and hydrothermal temperature on the microstructures and photocatalytic activity of the $\mathrm{TiO}_{2}$ powders were investigated. The results suggest that increasing the oil/water emulsion ratio significantly decreased the particle size of the as-prepared $\mathrm{TiO}_{2}$ powders and improved the photocatalytic activity. With hydrothermal temperature increasing, the average crystallite size increased and the photocatalytic activities of $\mathrm{TiO}_{2}$ powders decreased.
\end{abstract}

\section{Keywords}

Titanium Dioxide; Microemulsion; Hydrothermal Method; Photocatalytic Activity

\section{Introduction}

The excellent performance of semiconducting oxide materials in the photocatalytic realm has attracted scientific interest for ongoing research [1]. As an important n-type semiconductor material, nano- $\mathrm{TiO}_{2}$ has recently stimulated increasing attention because of their promising applications in many fields, including sensors [2],

*Corresponding author.

How to cite this paper: Xu, X.Y., Zhou, X.S., Ma, L., Mo, M.Y., Ren, C.F. and Pan, R.K. (2014) One-Step Microemulsion-Mediated Hydrothermal Synthesis of Nanocrystalline $\mathrm{TiO}_{2}$. World Journal of Nano Science and Engineering, 4, 29-34. 
self-cleaning photocatalytic surfaces and devices [3], dye-sensitized solar cells [4], environmental purification and hydrogen generation by water photoelectrolysis [5] [6]. Fundamental researches regarding the preparation of photocatalyst with highly photocatalytic activity, the immobilization of powder photocatalyst, and the improvement of photocatalyst performance are priorities to be considered [7].

Many methods, such as hydrolysis (chemical precipitation) [8], reverse micelles (microemulsion) [9] [10], sol-gel [11] [12] and hydrothermal crystallization [13]-[15], have been used to prepare $\mathrm{TiO}_{2}$ nanocrystalline photocatalyst. These methods suffer the problems of high-temperature processing, long aging time, grain growth and vigorous stirring. The high processing temperatures and long reaction time result in the formation of large sized particles with a wide size distribution [16]. Consequently, it is in need of developing a novel and environmentally benign approach to preparing $\mathrm{TiO}_{2}$ nanocrystalline photocatalyst. In this paper, a new one-step strategy by microemulsion-mediated low temperature hydrothermal route has been employed to synthesize crystalline nanosized $\mathrm{TiO}_{2}$ powders. The main advantage of the proposed route is low reaction temperature and short processing time that prevents agglomeration in the formed particles. Varying oil/water microemulsion ratio, nano-sized $\mathrm{TiO}_{2}$ particles with large surface area and a cuboid-liked shape were successfully synthesized at low temperature within short reaction period. The effects of hydrothermal processing temperature or time on the microstructures and photocatalytic behavior of the obtained $\mathrm{TiO}_{2}$ powders were also investigated in detail.

\section{Experimental Section}

\subsection{Preparation of the Catalysts}

In a typical synthesis, $40 \mathrm{ml}$ cyclohexane, $12 \mathrm{ml} \mathrm{n}$-butanol, $8 \mathrm{ml}$ polyoxyethylene (10) octylphenyl ether (OP-10), $4 \mathrm{ml}$ tetrabutyl titanate and $4 \mathrm{ml} \mathrm{HCl}(0.1 \mathrm{M})$ were mixed together to form a dispersed mixture. After stirring for about $30 \mathrm{~min}$, the mixture was finally transferred into a $100 \mathrm{ml}$ Teflon-lined stainless steel autoclave. It was sealed tightly and maintained at $120^{\circ} \mathrm{C}$ for $1 \mathrm{~h}$. After that, the autoclave was allowed to cool down naturally. The products were collected and washed three times using deionized water and absolute ethanol, then dried for $12 \mathrm{~h}$ under vacuum at $60^{\circ} \mathrm{C}$. The as-synthesized samples were denoted as TX-Y (X denotes the oil/water ratio, and Y denotes the hydrothermal temperature).

\subsection{Characterization of the Catalysts}

XRD analysis was performed on a D/Max-2550 X-ray diffractometer with monochromatized CuK $\alpha$ radiation ( $\lambda$ $=0.1540562 \mathrm{~nm}$ ). TEM was recorded on a transmission electron microscopy (TEM, JEOL JEM-200CX). The Brunauer-Emmett-Teller (BET) surface area $\left(S_{\mathrm{BET}}\right)$ was determined by nitrogen adsorption-desorption isotherm measurements at $77 \mathrm{~K}$ on a Micromeritics ASAP 2010 system. The samples were degassed in vacuum at $473 \mathrm{~K}$ until a pressure lower than $10^{-6}$ Torr before the actual measurements.

\subsection{Photocatalyst Reaction}

The photocatalytic reaction was conducted in the XPA-II photochemical reactor (Nanjing Xujiang Machineelectronic Plant). A $1000 \mathrm{~W}$ Xe lamp was used as the simulated solar light source, and a house-made filter was mounted on the lamp to eliminate infrared irradiation. MB $(20 \mathrm{mg} / \mathrm{L})$ was used as contamination. $20 \mathrm{mg}$ photocatalyst powder was dispersed in $200 \mathrm{~mL}$ reaction solutions by ultrasonicating for $15 \mathrm{~min}$, then the suspension was magnetically stirred in dark for $1 \mathrm{~h}$. Air was blown into the reaction medium at a flow rate of $200 \mathrm{~mL} / \mathrm{min}$ during the photocatalytic reaction. One $8 \mathrm{~mL}$ of the suspension was sampled and filtered. The concentration of the remaining MB was measured by a Hitachi UV-3010 spectrophotometer. The degradation ratio was calculated by $\mathrm{X}=\left(\mathrm{A}_{0}-\mathrm{A}\right) / \mathrm{A}_{0} \times 100 \%$.

\section{Results and Discussion}

\subsection{Morphology and Structures of the Samples}

Figure 1(a) shows the XRD patterns of nano-sized $\mathrm{TiO}_{2}$ powders prepared by one-step microemulsion-mediated hydrothermal route at $120^{\circ} \mathrm{C}$ for $1 \mathrm{~h}$. All samples show pure anatase phase, which was not affected by the change in the oil/water ratio. The anatase crystal sizes were calculated by the Scherrer equation (Table 1). The XRD peaks of the obtained $\mathrm{TiO}_{2}$ powders became broader with increasing the microemulsion oil/water ratio. 
Table 1. Experimental conditions, SBET and particle size of the as-prepared samples.

\begin{tabular}{ccccc}
\hline Samples & $\begin{array}{c}\mathbf{R}=\text { oil/water } \\
\text { (volume) }\end{array}$ & $\begin{array}{c}\text { Hydrothermal } \\
\text { temperature }\left({ }^{\circ} \mathbf{C}\right)\end{array}$ & $\begin{array}{c}\mathbf{S}_{\mathrm{BET}} \\
\left(\mathbf{m}^{\mathbf{2}} \cdot \mathbf{g}^{-\mathbf{1}}\right)\end{array}$ & $\begin{array}{c}\text { Particle size } \\
(\mathbf{n m})\end{array}$ \\
\hline $\mathrm{T} 2-120$ & 2 & 120 & 232 & 22.8 \\
$\mathrm{~T} 5-120$ & 5 & 120 & 294 & 14.3 \\
$\mathrm{~T} 10-120$ & 10 & 120 & 300 & 9.6 \\
T10-140 & 10 & 140 & 287 & 16.5 \\
T10-160 & 10 & 160 & 259 & 19.4 \\
\hline
\end{tabular}

The broad diffraction peaks implied decrease in the particle size of $\mathrm{TiO}_{2}$ powders.

Figures 1(b)-(d) show TEM micrographs of the as-prepared samples T2-120, T5-120 and T10-120. It is revealed that the morphology of the obtained $\mathrm{TiO}_{2}$ particles was mono-dispersed. When the oil/water ratio was increased, the average particle sizes of the $\mathrm{TiO}_{2}$ powders decreased, which were consistent with XRD result. It was reported that the size of the reverse micelle depends on the amount of water content in the microemulsion solution [17]. Once the oil/water ratio is increased, the size of the reverse micelle is correspondingly decreased. Since the grain growth of particles is limited by the size of the reverse micelles in the microemulsion hydrothermal process, increasing the oil/water ratio ultimately decreases the size of the $\mathrm{TiO}_{2}$ particles formed therein.

Figure 2(a) depicts the XRD patterns of $\mathrm{TiO}_{2}$ powders synthesized from one-step microemulsion-mediated solution after hydrothermally treated at $120^{\circ} \mathrm{C}, 140^{\circ} \mathrm{C}$, and $160^{\circ} \mathrm{C}$ for $1 \mathrm{~h}$. The XRD patterns indicate that anatase phases were formed in all samples. It was observed that with increasing hydrothermal processing temperatures, the peak intensities increased and the full width half maximum of the diffraction peak became narrower. This reveals that the crystallite size increased with increasing hydrothermal temperatures. This indicates the increase in the formation of larger crystallites and anatase phase crystallinity enhancement in the formed $\mathrm{TiO}_{2}$ powders at elevated hydrothermal temperatures. Yu et al. also reported that the average crystallite sizes and degree of crystallization increase with increasing hydrothermal temperatures [18].

Figures 2(b)-(d) show TEM micrographs of the as-prepared samples hydrothermally treated at $120^{\circ} \mathrm{C}, 140^{\circ} \mathrm{C}$ and $160^{\circ} \mathrm{C}$. It can be seen that after increasing the hydrothermal temperature to $160^{\circ} \mathrm{C}$ (Figure 2(d)), the $\mathrm{TiO}_{2}$ particles retained the cuboid-like morphology. In addition, the particle size was found to be increased after the hydrothermal temperature was raised. With increasing hydrothermal temperature, the reverse micelles in the microemulsion will not be maintained. This will result in fast cluster nucleation oriented in random directions, thereby forming large particles [19].

\subsection{Photocatalytic Activities of Samples}

Figure 3 shows the comparison of photocatalytic activity of the $\mathrm{TiO}_{2}$ powders synthesized in different hydrothermal conditions. The photocatalytic activity of Degussa P-25 powders, which is recognized as an excellent photocatalyst, was also measured as a reference to compare with that of the as-prepared catalysts. The BET specific surface areas of $\mathrm{TiO}_{2}$ powders are shown in Table 1. It is revealed that the amount of methylene blue degraded by $\mathrm{TiO}_{2}$ powders was increased when the oil/water ratio was raised. This is attributed to the increase in BET specific surface area of $\mathrm{TiO}_{2}$ powders as reported by $\mathrm{Yu}$ et al. [20]. It can be seen that not all of the as-prepared $\mathrm{TiO}_{2}$ powders had a greater photocatalytic activity than that of Degussa P-25. The photocatalytic activity should be a function of many physical parameters including the BET surface area, pore size and distribution, crystal size, crystalline, etc [18]. Therefore, the highest activities of the prepared $\mathrm{TiO}_{2}$ powders at $120^{\circ} \mathrm{C}$ for $1 \mathrm{~h}$ could be attributed to the results of the above mentioned synergistic effects.

\section{Conclusion}

In summary, $\mathrm{TiO}_{2}$ nano-particles with improved photocatalytic performance were successfully prepared via a one-step microemulsion hydrothermal process. The advantage of using this microemulsion mediated hydrothermal route is the significant reduction in reaction time and temperatures compared with the conventional hydrothermal process. Nanocrystalline $\mathrm{TiO}_{2}$ powders with high photocatalytic activity were obtained after the hydrothermal treatment. The oil/water ratio and hydrothermal temperature obviously influenced the microstructures and photocatalytic activity of the as-prepared $\mathrm{TiO}_{2}$ powders. Increasing the oil/water emulsion ratio 

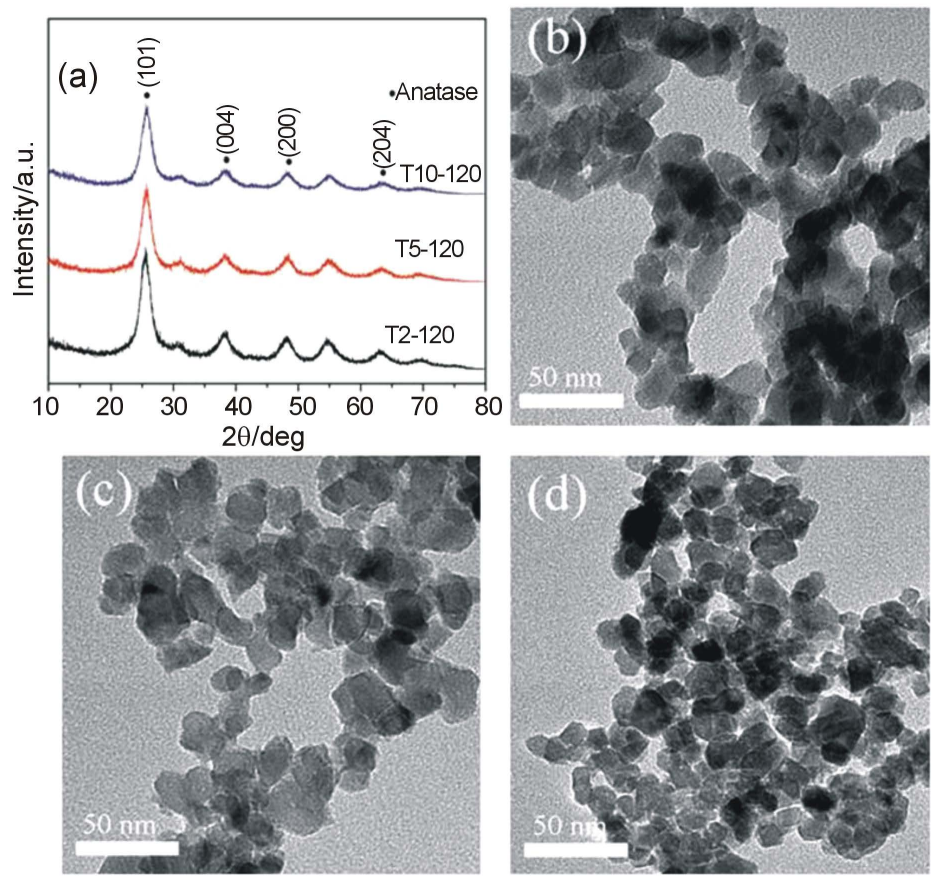

Figure 1. XRD pattern (a) and TEM images of the as-prepared samples: (b) T2-120; (c) T5-120 and (d) T10-120.
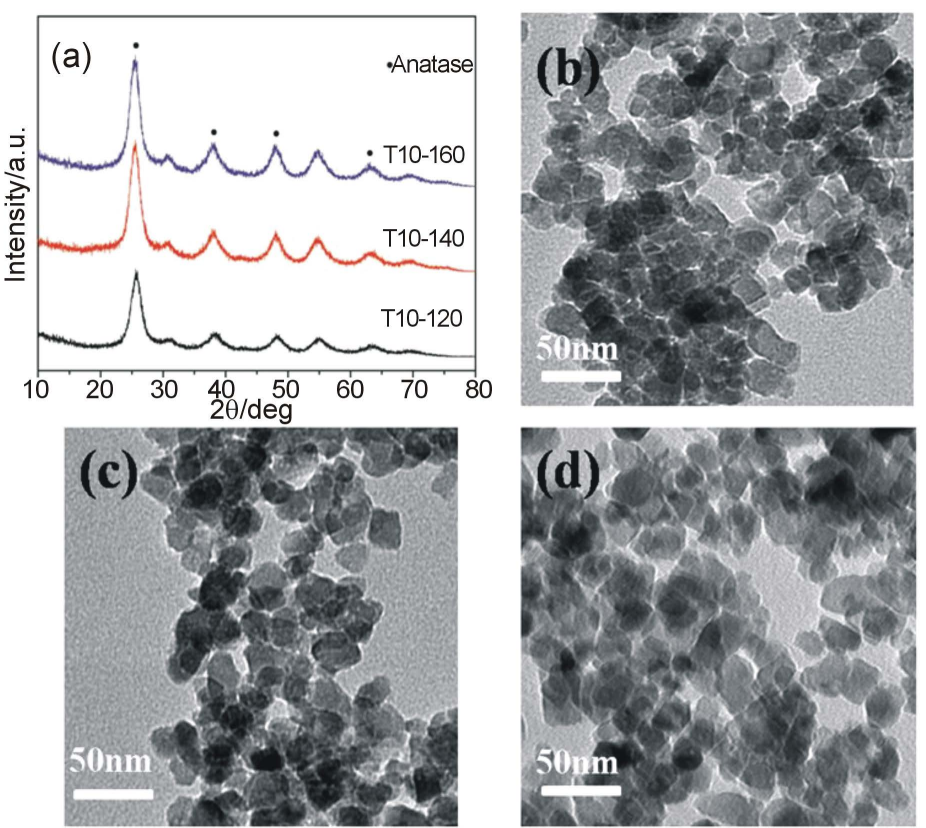

Figure 2. XRD pattern (a) and TEM images of the as-prepared samples: (b) T10-120; (c) T10-140 and (d) T10-160.

significantly decreased the particle size of the prepared $\mathrm{TiO}_{2}$ powders and improved the photocatalytic activity. With increasing hydrothermal temperature, the average crystallite size increased. In contrast, the BET specific surface areas steadily decreased. Consequently, the photocatalytic activities of $\mathrm{TiO}_{2}$ powders were reduced with hydrothermal temperature elevation. Our experimental results indicate that the photocatalytic activity of the $\mathrm{TiO}_{2}$ powders prepared under an optimal hydrothermal condition (T10-120) exceeded that of Degussa P-25 powders. 


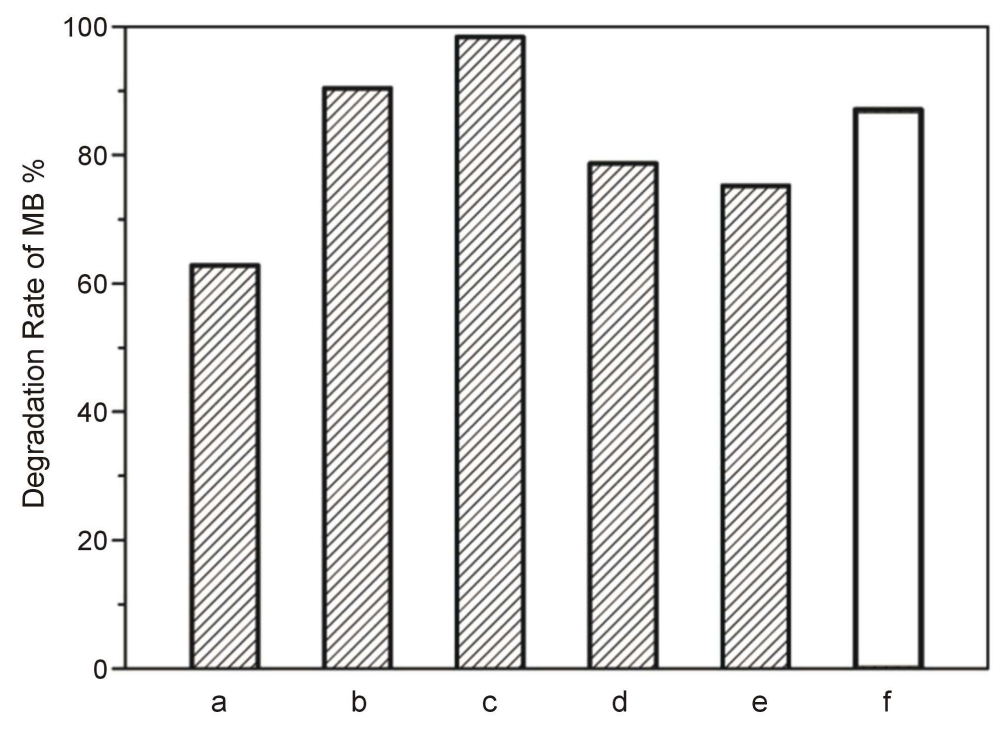

Figure 3. Comparison of degraded methylene blue rate of $\mathrm{TiO}_{2}$ powders prepared in different hydrothermal treatment for $2.5 \mathrm{~h}$ : (a) T2-120; (b) T5-120; (c) T10-120; (d) T10-140; (e) T10-160 and (f) P-25.

\section{Acknowledgements}

This work was financially supported by Zhanjiang Science and Technology Research Projects (No. 2013B01152), Zhanjiang Normal University Natural Science Foundation for the Youth Program (No. L1202), Guangdong Natural Science Foundation for Ph.D Start-up Research Program (S2013040013755), and Colleges and Universities in Guangdong Province Science and Technology Innovation Project (2013KJCX0123).

\section{References}

[1] Lu, N., Quan, X., Li, J.Y., Chen, S., Yu, H.T. and Chen, G.H. (2007) Fabrication of Boron-Doped TiO 2 Nanotube Array Electrode and Investigation of Its Photoelectrochemical Capability. The Journal of Physical Chemistry C, 111, 11836-11842. http://dx.doi.org/10.1021/jp071359d

[2] Gouma, P.I., Mills, M.J. and Sandhage, K.H. (2000) Fabrication of Free-Standing Titaniabased Gas Sensors by the Oxidation of Metallic Titanium Foils. Journal of the American Ceramic Society, 83, 1007-1009.

http://dx.doi.org/10.1111/j.1151-2916.2000.tb01320.x

[3] Kamegawa, T., Shimizu, Y. and Yamashita H., (2012) Superhydrophobic Surfaces with Photocatalytic Self-Cleaning Properties by Nanocomposite Coating of $\mathrm{TiO}_{2}$ and Polytetrafluoroethylene. Advanced Materials, 24, 3697-3700. http://dx.doi.org/10.1002/adma.201201037

[4] Tan, B. and Wu, Y. (2006) Dye Sensitized Solar Cells Based on Anatase $\mathrm{TiO}_{2}$ Nanoparticle/Nanowire Composites. The Journal of Physical Chemistry B, 110, 15932-15938. http://dx.doi.org/10.1021/jp063972n

[5] Venkatachalam, N., Palanichamy, M. and Murugesan, V. (2007) Sol-Gel Preparation and Characterization of Alkaline

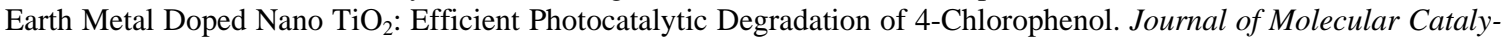
sis A, 273, 177-185. http://dx.doi.org/10.1016/j.molcata.2007.03.077

[6] Allam, N.K., Alamgir, F. and El-Sayed, M.A. (2010) Enhanced Photoassisted Water Electrolysis Using Vertically Oriented Anodically Fabricated Ti-Nb-Zr-O Mixed Oxide Nanotube Arrays. ACS Nano, 4, 5819-5826. http://dx.doi.org/10.1021/nn101678n

[7] Yu, J.G., Su, Y.R., Cheng, B. and Zhou, M.H. (2006) Effects of pH on the Microstructures and Photocatalytic Activity of Mesoporous Nanocrystalline Titania Powders Prepared via Hydrothermal Method. Journal of Molecular Catalysis A, 258, 104-112. http://dx.doi.org/10.1016/j.molcata.2006.05.036

[8] Borse, P.H., Kankate, L.S., Dassenoy, F., Vogel, W., Urban, J. and Kulkarni, S.K. (2002) Synthesis and Investigations of Rutile Phase Nanoparticles of $\mathrm{TiO}_{2}$. Journal of Materials Science, 13, 553-559. http://dx.doi.org/10.1023/A:1019677730981

[9] Hong, S.S., Lee, M.S. and Lee, G.D. (2003) Photocatalytic Decomposition of p-Nitrophenol over Titanium Dioxide Prepared by Reverse Microemulsion Method Using Nonionic Surfactants with Different Hydrophilic Groups. Reaction 
Kinetics and Catalysis Letters, 80, 145-151. http://dx.doi.org/10.1023/A:1026096628817

[10] Keswani, R.K., Ghodke, H., Sarkar, D., Khilar, K.C. and Srinivasa, R.S. (2010) Room Temperature Synthesis of Titanium Dioxide Nanoparticles of Different Phases in Water in Oil Microemulsion. Colloid Surface A, 369, 75-81. http://dx.doi.org/10.1016/j.colsurfa.2010.08.001

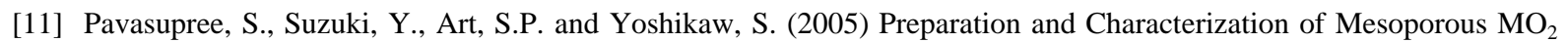
( $\mathrm{M}=\mathrm{Ti}$, Ce, Zr, and Hf) Nanopowders by a Modified Sol-Gel Method. Ceramics International, 31, 959-963. http://dx.doi.org/10.1016/j.ceramint.2004.10.009

[12] Venkatchalam, N., Palanichamy, M. and Murugesan, V. (2007) Sol-Gel Preparation and Characterization of Nanosize $\mathrm{TiO}_{2}$ : Its Photocatalytic Performance. Materials Chemistry and Physics, 104, 454-459. http://dx.doi.org/10.1016/j.matchemphys.2007.04.003

[13] Yu, J.G., Zhang, L.J., Cheng, B. and Su, Y.R. (2007) Hydrothermal Preparation and Photocatalytic Activity of Hierarchically Sponge-Like Macro-/Mesoporous Titania. The Journal of Physical Chemistry C, 111, 10582-10589. http://dx.doi.org/10.1021/jp0707889

[14] Kobayashi, M., Petrykin, V., Tomita, K. and Kakihana, M. (2011) Hydrothermal Synthesis of Brookite-Type Titanium Dioxide with Snowflake-Like Nanostructures Using a Water-Soluble Citratoperoxotitanate Complex. Journal of Crystal Growth, 337, 30-37. http://dx.doi.org/10.1016/j.jcrysgro.2011.09.046

[15] Yin, H., Ding, G.Q., Gao, B., Huang, F.Q., Xie, X.M. and Jiang, M.H. (2012) Synthesis of Ultrafine Titanium Dioxide Nanowires Using Hydrothermal Method. Materials Research Bulletin, 47, 3124-3128. http://dx.doi.org/10.1016/j.materresbull.2012.08.022

[16] Lu, C.H., Wu, W.H. and Kale, R.B. (2008) Microemulsion-Mediated Hydrothermal Synthesis of Photocatalytic TiO ${ }_{2}$ Powders. Journal of Hazardous Materials, 154, 649-654. http://dx.doi.org/10.1016/j.jhazmat.2007.10.074

[17] Lisiecki, I. and Pileni, M.P. (1993) Synthesis of Copper Metallic Clusters Using Reverse Micelles as Microreactors. Journal of the American Chemical Society, 115, 3887-3896. http://dx.doi.org/10.1021/ja00063a006

[18] Yu, J., Wang, G., Cheng, B. and Zhou, M. (2007) Effects of Hydrothermal Temperature and Time on the Photocatalytic Activity and Microstructures of Bimodal Mesoporous $\mathrm{TiO}_{2}$ Powders. Applied Catalysis B, 69, 171-180. http://dx.doi.org/10.1016/j.apcatb.2006.06.022

[19] Zhang, P. and L. Gao, (2003) Synthesis and Characterization of CdS Nanorods via Hydrothermal Microemulsion. Langmuir, 19, 208-210. http://dx.doi.org/10.1021/la0206458

[20] Yu, J., Su, Y. and Cheng, B. (2007) Template-Free Fabrication and Enhanced Photocatalytic Activity of Hierarchical Macro-/Mesoporous Titania. Advanced Functional Materials, 17, 1984-1990. http://dx.doi.org/10.1002/adfm.200600933 